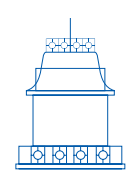

RESEÑ A

\title{
Cortés, F. (2020). Del arte de la paz: reflexiones filosóficas sobre justicia transicional. Siglo del Hombre
}

\author{
Carlos Thiebaut \\ Universidad Carlos III de Madrid, Madrid, España \\ E-mail: carlos.thiebaut@uc3m.es | ORCID: 0000-0003-3391-5496 \\ https://doi.org/10.17533/udea.ef.n63a10
}

He leído con pasión, con pasión ciudadana y con pasión filosófica, la reflexión de Francisco Cortés sobre los procesos y problemas de la justicia transicional en Colombia. Pasión ciudadana porque, aunque no sea mi país, me hallo cercano a él y porque los problemas que aborda son ya universales. El proceso de paz colombiano es uno de esos quicios de la historia en el que también está concernida toda concepción cosmopolita. Pero también, esa pasión ciudadana tiene un eco en mi país, España. España ha sido maestra en eludir, y tropezar, y volverse a enfrentar a su inconclusa memoria histórica. En el análisis que hace Francisco Cortés, esos vericuetos de la memoria están presentes de múltiples maneras y las maneras en las que la sociedad colombiana está lidiando con ellos me parecen fascinantemente ejemplares, por muchas dificultades y fallos que hayan podido tener.

No es solo el recordar, el no olvidar, el tener o el hacer presentes la violencia que se amontona aterradoramente en el pasado -que también-, sino la carga normativa de todas las demandas que se acumulan en los daños realizados, en las demandas de atención, de cuidado, de reparación, que traen consigo lo que sostenemos o recuperamos en la memoria. Ubicar en el amplio contexto de la humanidad este proceso de recuerdo del daño y el trabajo de su clausura, el sentido cosmopolita al que me refería, y que me concierne como ciudadano del mundo, me parece especialmente relevante y está presente en el libro de Francisco de múltiples maneras: en esto que estoy llamando la pasión ciudadana que comparto con él, a pesar de las diferencias entre nuestros países y nuestras historias, en esa pasión cosmopolita su libro traza y se ubica en 
una larga genealogía de maneras de enfrentarnos al daño en los procesos de justicia transicional. Francisco traza, así, la historia de esas elaboraciones; en Nüremberg tras el Holocausto; en Sudáfrica, tras la caída del apartheid; en los procesos de transición tras las dictaduras latinoamericanas y ubica en ellas el proceso colombiano. Muestra las diferencias de esas y otras diversas estrategias de resolución, en lo que Lawrence Douglas (2001) ha llamado The memory of judgment, la memoria del juicio, o la memoria de nuestra capacidad de juzgar y la memoria de nuestros juicios -juicios penales- a la hora de dirimir las responsabilidades por los daños infligidos.

Como he indicado, percibo - quizá otro rasgo más de mi moral resistente e ilustradauna genealogía de aprendizajes en ese camino. Pero no es solo mi percepción, pues en casi cada documento de esos y otros procesos transicionales, hay referencias a esa historia de aprendizaje que es la de dar forma jurídica a la clausura de los daños de la historia. La idea que apunto es que tanto cuando dirimimos la responsabilidad por los daños -quién lo hizo, por qué, cómo puede esa persona o esa institución compensar o reparar lo que hiciera-como cuando, como terceras figuras de la experiencia del daño, atendemos a la reparación de esos daños y establecemos las formas de su no reiteración en el futuro, empleamos, y no podemos no emplear, conceptos, normas, instituciones, que se van modificando en la historia $-y$, en un sentido relevante, van, por así decirlo, aprendiendo, atendiendo a las circunstancias particulares, históricas, sociales, de la realidad de aquellos daños y puliendo los conceptos, las normas y los procedimientos para atender las formas específicas de esos daños en esos contextos. Y eso implica, entonces, tanto mostrar una larga cadena de aprendizajes y de continuidades como indicar las diferencias y las particularidades de ese camino. Francisco muestra nexos, pero también diferencias. Quizá, con el afán de mostrar lo específico del proceso de paz colombiano, acentúa más estas diferencias que las continuidades. Así lo hace no ya con las condenas del nazismo sino también con los procesos de amnistía que tuvieron lugar en la Comisión de Verdad y Reconciliación de Sudáfrica (TRC, Truth and Reconciliation Commission). Yo percibo más continuidades entre la comisión de amnistía de la TRC - se le garantizaba amnistía a los perpetradores, de todas las partes del conflicto, a cambio del reconocimiento público de sus actos y de la explicitación de su motivación política-y los instrumentos que se han implementado en Colombia que las que ve Francisco. Y podría argumentarlo con más detenimiento, pero desde luego coincido con él en que los factores que señala de la especificidad del caso colombiano hacen que sus procesos de justicia y de paz hayan de ser específicos y diferentes. Porque, en primer lugar, la violencia de Colombia ha tenido la forma de una guerra y el primer imperativo ha sido, consiguientemente, el de la paz. No es ese el contexto de otros procesos de fin de la violencia, como el sudafricano que mencionaba. ${ }^{1}$ De ello se

1 También, obviamente, podemos matizar lo que significa "guerra" en diferentes contextos; empleo el término para referirme a enfrentamientos sistemáticos de grupos armados —y en el caso colombiano, como fue el español, dentro de la misma sociedad; 
deducen consecuencias importantes: los procesos de paz deben ser llevados a cabo con los grupos enfrentados como sujetos de los mismos; no pueden ni ser impuestos ni traídos de fuera. Y para que esos sujetos puedan acordar la paz, también esos sujetos deben acordar las formas jurídicas de la atribución de responsabilidades y de cooperación en las formas de restauración de la convivencia cívica quebrada.

Y aquí entra la pasión filosófica con la que he leído el libro de Francisco, que es el trabajo de un filósofo que indaga por los conceptos y las teorías que sostienen las prácticas de atribución de responsabilidad y de restauración de la convivencia cívica. El libro parte, precisamente, de discutir las diversas nociones de justicia que se han puesto en evidencia en la discusión de los Acuerdos de Paz. Francisco hace, creo, un excelente trabajo en señalar que quienes se oponían a los Acuerdos de Paz, y aún lo hacen, con el argumento de que los acuerdos de La Habana simplemente garantizaban una amnistía a las FARC que no se merecían y que, por lo tanto, esos acuerdos son moral, pero sobre todo jurídicamente, cuestionables y fallidos. Francisco muestra de manera adecuada que ese cuestionamiento se basa en una concepción retribucionista de la justicia (y de la justicia penal) y que esa concepción es inadecuada para las tareas de la paz tras esa forma de violencia armada en un conflicto fraticida. Aquí entramos en aguas profundas, que me inquietan mucho como filósofo. Porque el retribucionismo -que hunde sus raíces en la lógica casi vengativa del ojo por ojo- ha ido modificándose en la historia de los conceptos y de las doctrinas hasta convertirse, a pesar de muchas derivas y discusiones, en la concepción básica del derecho penal. Les confieso que a mí el retribucionismo siempre me pareció una doctrina oscura. ¿Se merece el castigo un perpetrador? ¿Qué se consigue castigándolo por esa razón? El libro de Francisco hace un buen trabajo mostrando que esa concepción de la justicia no es adecuada para un proceso transicional como el colombiano que, más bien, debería operar con una concepción restauradora o restaurativa de la justicia.

Me interesa y apasiona esa concepción restaurativa de la justicia. En España se intentó - pero fueron procesos muy localizados, muy particularizados- con los encuentros restaurativos entre victimarios y víctimas del terrorismo etarra. Nos encontramos con fuertes resistencias retributivas, por así llamarlas, de quienes sostenían y sostienen que la derrota del terrorismo etarra sólo requería la aplicación estricta del código penal y que dejaban en los márgenes, en las relaciones personales, casi terapéuticas, esos encuentros. Rechazaban, y rechazan, que esos encuentros pudieran ni siquiera tener un carácter emblemático para la sociedad vasca y española. Yo mismo no lo tengo del todo claro, y sostengo una concepción penal estricta en el castigo de los delitos terroristas. En nuestro caso español el terrorismo etarra no fue, en esas décadas afortunadamente pasadas cuyo significado aún rumiamos,

por eso la colombiana y la española fueron guerras civiles. Probablemente, las disputas sobre el proceso de paz colombiano tienen que ver con esta forma de conceptualizarlo. 
un conflicto de guerra civil, a diferencia de nuestra guerra en los años treinta del siglo pasado que aún nos pesa. Pero, creo que la vía restaurativa - ponerse todos los implicados a reconstruir el tejido social dañado, reparándolo- tiene una potencia aún no del todo explorada. Pero, de manera interesante, sospecho, hay un terreno común entre el retribucionismo de vieja escuela, por así llamarlo - ¡nada menos que el que hunde sus raíces ilustradas en Kant, aunque Kant tenga una concepción del retribucionismo más sutil y republicana, que Francisco resalta y reconstruye acertadamente!- y las concepciones restaurativas. Estas requieren y suponen que víctimas y victimarios se conciban, por diversas que sean sus razones y sus motivos, como partes implicadas en un mismo proceso de restauración del orden cívico, de reparación moral, cívica y jurídica de esa convivencia. Y, entonces, como apunta Francisco - pero me hubiera gustado mayor desarrollo de esa posibilidad- algunas doctrinas del retribucionismo expresivo, como la Jean Hampton (1992), vienen al caso: porque sostienen que tanto el victimario o quien dañó busca y se "merece" el castigo como forma de una reparación que él mismo asume ya como propio. Intuyo que hay un terreno común y abierto entre esa búsqueda de quien dañó y la reparación que la víctima necesita. E incluso cabe pensar que el victimario mismo también la necesita. Esa idea de un retribucionismo expresivo adquiere, si puede, más fuerza si puede mostrarse que eso que estoy llamando victimarios también necesitan (nótese, no merecen) la restauración que la paz pudiera traer consigo, incluso con el pago de una pena por sus violaciones de los derechos.

Permítanme una aclaradora cita del libro de Francisco Cortés al respecto (2020, p. 115):

En la perspectiva de la justicia restaurativa se afirma, de un lado, que en un proceso transicional el sufrimiento de las víctimas debe ser reconocido mediante una vía distinta a la retributiva; de otro lado, que los perpetradores se deben responsabilizar frente a las exigencias de justicia, verdad y reparación de las víctimas; además, que los transgresores deben realmente arrepentirse y buscar así el perdón de sus víctimas; por último, que la justicia no requiere necesariamente la implementación de medidas punitivas, pues con un mecanismo como la Comisión de la Verdad es posible que los ciudadanos, apelando a sus propias tradiciones culturales, logren la justicia, la verdad y la reparación. El esclarecimiento de la verdad y el establecimiento de hechos históricos podrían alcanzarse con independencia de un proceso penal e incluso con mayor eficacia que en este.

Quizá ese delicado entramado conceptual -el del merecimiento del castigo, el de la necesidad de la restauración y la reparación- acude a unos lenguajes que, en nuestras culturas, están cargados de significados religiosos: la confesión de que en verdad ocurrió, el arrepentimiento, el perdón. Creo que tenemos que operar aquí con un delicado equilibrio: no creo que podamos, ni debamos, renunciar a esos términos, por cargados que estén de simbolizaciones religiosas, pero debemos tener cuidado con no extraer consecuencias institucionales que, creo, no son deseables. El 
arrepentimiento y el perdón son actitudes, prácticas performativas, que realizamos las personas en las relaciones interpersonales. "Me duele lo que te hice y te pido perdón" pudiera ser un enunciado que tiene sentido tras un conflicto o un desencuentro -e incluso tras un acto condenable de violencia- con otra persona. La otra persona -la víctima, incluso- tiene el privilegio y la carga de aceptar ese acto comunicativo, o no. Pero ese orden de restauración, si se alcanza, de los vínculos interpersonales no es equivalente a los procesos de restauración del orden cívico que requiere la justicia, y aún más la justicia transicional. En el orden cívico restaurado requerimos de todas las partes, de acuerdo con su grado de responsabilidad, la asunción de su carga, su necesidad de la paz, y lo que se restaura en ese orden es la confianza de que todos, todas las partes, nos atengamos a las normas y leyes que regulen nuestra convivencia. No podemos exigir - a no ser que tengamos una concepción en exceso comunitarista del orden cívico, y las religiones tienden a ser comunitaristas- que coincidamos en los valores, las motivaciones, los significados, con todos, incluidos sobre todo con los anteriores victimarios. El objetivo es que todos nos atengamos a un orden de paz -que se proscriba y evite la violencia-y que todos nos atengamos a sostener la convivencia bajo la ley: eso es restaurar la convivencia, que es restaurar la confianza.

Concluyo. Mi pasión ciudadana y mi pasión filosófica aprenden cada día del proceso colombiano. Las amenazas crecientes de la nueva violencia que inunda su país me inquietan, me irritan, me indignan y me producen una herida desolación, como a ustedes. Pero desearía, quisiera pensar, que no interrumpen las implementaciones de su proceso de paz, ni en lo que tienen de ejercicio de la justicia ni en lo que tienen de desvelamiento, de puesta en público, de la verdad de los sufrimientos que el pueblo colombiano ha vivido.

\section{Referencias}

Cortés, F. (2020). Del arte de la paz: reflexiones filosóficas sobre justicia transicional. Siglo del Hombre.

Douglas, L. (2001). The Memory of Judgement. Making Law and History in the Trials of the Holocaust; New Haven, Yale University Press.

Hampton, J. (1992). An Expressive Theory of Retribution. In Cragg, W. (Ed.), Retributivism and Its Critics (pp. 1-25). Franz Steiner Verlag. 